\title{
PREHOSPITAL CPR TRAINING PERFORMED WITH VISUAL FEEDBACK
}

\author{
Anna Abelsson ${ }^{1}$, Lars Lundberg ${ }^{2}$ \\ 1 Jönköping University, School of Health Sciences, Jönköping, Sweden \\ ${ }^{2}$ University of Borås, Prehospen-Centre for Prehospital Research, Borås, Sweden
}

\begin{abstract}
INTRODUCTION: Swedish firefighters are a part of the emergency medical services. Therefore, they perform prehospital cardiopulmonary resuscitation (CPR) on a regular basis. Training becomes crucial for maintaining the CPR skills and increasing the patients' chances of survival. Training with visual feedback is for Swedish firefighters a new way of training CPR. The aim of this study was to evaluate firefighters' perception of a CPR manikin with visual feedback.
\end{abstract}

METHOD: This study had a qualitative approach. Data were collected by interviews with 16 firefighters after performing CPR on a manikin with visual feedback. The data were analyzed with a manifest content analysis.

RESULTS: Visual feedback makes it easy to identify and maintain correct compression rate. There is a need for identifying too deep compressions. Uncertainty regarding the closeness to the stomach arises when using the whole hand during compressions instead of just the wrist. To accomplish an open airway requires a bit of adjustment of the manikins' head.

DISCUSSION: To train and learn CPR is feasible with visual feedback. The firefighters can maintaing a correct compression rate and correct compression depth during the sessions. Ventilating a patient with bag-valvemask or pocket mask may require training with visual feedback to guarantee the firefighters being able to secure an open airway of the patient. All these skills are essential and improve the chance of survival for the patients.

KEY WORDS: firefighter, emergency medical service, CPR, manikin, visual feedback

Disaster Emerg Med J 2018; 3(2): 41-45

\section{INTRODUCTION \& AIMS}

The Swedish emergency medical service (EMS) includes ambulance, fire brigade and to some extent police. The ambulance is responsible for the prehospital emergency care and the fire brigade assist in any way possible. All firefighters, both full-time and part-time employees, have a medical education and meet the requirements to work as a Basic Emergency Medical Technicians (B-EMT). All fire trucks are equipped with medical supplies and automated external defibrillators (AED).
The CPR is performed accordingly to European Resuscitation Council Guidelines for Resuscitation $[1,2]$. CPR comprise of chest compressions performed at a depth of 5-6 centimeters with a rate of 100-120 compressions per minute. Ventilation consists in inflating patient's chest with air volumes of 400-700 milliliter within 1 second. The chest compression-ventilation ratio is $30: 2$ [1]. Ventilation of the patient is conducted by the Swedish firefighters using pocket masks or bag masks. 
Prior research has shown that shorter EMS response time might increase the survival of patients suffering from out-of-hospital cardiac arrest (OHCA) [3]. In Sweden, the dual dispatch of ambulance and firefighters in OHCA have significantly reduced response times and therefore, it significantly increased survival rate of patients suffering from OHCA $[4,5]$.

The quality of the CPR is important for the patient's chance of survival. The rescuer may have a good CPR technique but lack a feeling for correct compression rate and depth. Not being exposed to OHCA cases can become a barrier for EMS staff to maintain their resuscitation competency. Lack of CPR training has also been identified as a barrier for the EMS staff [6].

Therefore, training is essential for maintaining CPR skills. Firefighters seldomly perform CPR in a calm environment but rather in a chaotic, emergency situation at the scene of an accident. The training should be adapted to the different situations the rescuers work in $[7,8]$.

Receiving feedback of CPR improves CPR quality [9]. Training with visual feedback may help participants to create muscle memory for how a high-quality CPR should feel. The training in this study was performed with a new type of manikin providing visual feedback consisting of lights indicating the CPR quality. This study was performed in order to further tailor the CPR education and training for the fire department.

The aim of the study was to evaluate firefighters' perception of a CPR manikin with visual feedback.

\section{METHODS}

This study had a qualitative design. The participants consisted of 16 firefighters, all with EMT training, 15 males and 1 female. Data were collected during a schedule CPR practice. A Brayden Pro ${ }^{\circledR}$ manikin (Innosonian Europe) was used. The participants performed CPR for two minutes on the manikin with the visual light as feedback of the CPR quality. Participants did not get any feedback on their performance from the instructor. After CPR, the firefighters were asked to describe how they had perceived the CPR manikin with visual feedback.

\section{DATA ANALYSIS}

A methodological approach using manifest content analysis was followed [10]. In this approach, words and meaning expressed in the interviews were analyzed in three steps; preparation, organization and presentation. In the preparation step, the entire material was repeatedly read to get a deeper understanding of the text. In the second step, organization, meaning-bearing units were identified and then coded and sorted into categories based on differences and similarities. In the final step, presentation, the analysis process and results were thoroughly described [10].

The relevance of the result in this study has been verified by the correlation between the aim of the research and the categories [10]. This verification also enhanced credibility and transparency of the study [11]. The validity was strengthened by the text analysis performed in a systematic and replicable way [10]. The phenomenon in this study, firefighters' perception of a CPR manikin with visual feedback, has been presented in a profound way.

\section{ETHICAL CONSIDERATIONS}

The study followed the ethical principals in accordance with the World Medical Association about anonymity, integrity and maintaining of public confidence [12]. An ethics approval was obtained from the Federal General Manager of Fire and Rescue Services. The participants were informed of the study before being asked to consent. Informed consent was obtained from each participant.

\section{RESULTS}

\section{Compression rate}

In this study, chest compressions were considered easy to perform on the manikin. The participants described that it was easy to identify and maintain a compression rate within the correct CPR limits. Maintaining the compression rate was described as easy partly due to the patient-like feeling of the resistance in the manikin's torso and also partly due to the lights continuously indicating correct or incorrect compression rate.

Some participants described that the force needed for accomplishing compressions was perceived as somewhat low. This resulted in the feeling of the compression rate being performed slower than it actually was. The lights were therefore described as a good way to get feedback by the continuous indication of a correct compression rate. Some partici- 
pants described that they were uncertain whether to increase or decrease the compression rate without getting visual feedback. The manikin weight was lower than that of a person. It was therefore visible that it slid away from the participants when they performed compressions.

\section{Compression depth}

Regarding the depth of the compressions, the need for an indicator was pointed out to identify when the compressions were too deep.

\section{Hand position}

Compressions with a whole hand instead of the wrist were in this study described to give a better result of the hand position. However, the placement of the hands was considered to be indifferent to the manikin's torso. Sometimes the participants noticed that they were close to the manikin's stomach and still got an acceptable result for hand position.

\section{Ventilation}

The experience of ventilating the patient was described as positive. The airways and the lungs were easily expanded to a volume of $400-700 \mathrm{ml}$ during the insufflation when the airway was open. The manikin was described as resembling a patient when it came to clearing and maintaining an open airway. To accomplish an open airway of the manikin it required a bit of adjustment for the participants. It emerged how important it was to position the head in a correct position to establish an open airway and to successfully ventilate the patient.

\section{DISCUSSION}

\section{Compression rate}

Regarding the compression rate, the range of 100-120 compressions per minute is considered the optimal zone for survival of the patient [13] and therefore, essential to maintain. Identifying and maintaining the compression rate was in this study described as easy due to the light continuously indicating the correct compression rate. In contrast, Alves et al. shows how $80 \%$ of the firefighters in their study failed to maintain the compression rate of 100-120 per minute without any feedback devices [14]. The importance of maintaining the compression rate within $100-120$ is due to the interdependent relationship between compression rate and depth. As the rate increases, the depth decreases resulting in an impaired CPR quality [13].

The manikin was seen to slide away from the participants when they performed compressions. Regardless whether the manikin or the patient is placed on the slippery ground or not, when rescuers are distracted in some way, it has a negative effect on the quality of chest compression, in terms of its rate [15]. It is therefore important to place the patient on solid ground when performing CPR while waiting for the ambulance stretcher.

\section{Compression depth}

In the result, the participants expressed the need to identify when the compressions were too deep. Cheskes et al. describes how compression depth often exceeds $6 \mathrm{~cm}$ in a prehospital setting [16]. On the contrary, Stiell et al. describes how compressions are more likely to be too shallow when performed in a prehospital setting [17]. Regardless, previous studies have shown how an increased compression depth improves the likelihood of a favorable outcome for the patient [17-19]. The depth of the compression affects the increase in intrathoracic pressure and in turn lets the blood flow from the heart and great vessels to the systemic circulation [18].

\section{Hand position}

The placement of the hands was in this study considered to be indifferent to the manikin's torso. There are comparative studies evaluating resuscitation with hand position on the lower part of the sternum and on the center of the sternum $[20,21]$. These studies have not presented any conclusive results though. According to Kleinman et al., the rescuer's hand position will alter the mechanics of the compressions and in turn also affect the CPR quality [18]. This may also be a recording error in these kinds of studies. In a study of Truszewski et al., different feedback devices result in as much as $23 \%$ difference when compared regarding correct hand placement and the effect of the CPR quality [22].

\section{Ventilation}

The manikin resembled a patient in regard to clearing and maintaining an open airway. It required a bit of adjustment of the manikins' airways. To secure an open airway is essential for the Swedish firefighter since they use bag-valve-mask or pocket mask. This use of bag-valve-mask or pocket mask ventilation can be compared to other EMS where 
EMT's use i-gel or other types of supraglottic devices [23]. Studies show how staff at basic EMT level successfully places various models of supraglottic devices $[23,24]$. But there is always a risk in using a supraglottic device since failure in securing the airway is associated with a prolonged hands-off chest time during the CPR [25]. Kim et al. study also shows how the use of an airway device prolongs time at the scene [26].

\section{CONCLUSIONS}

To identify and maintain compression rate within correct CPR limits is essential for the survival of the patient. Feedback through lights continuously indicates a correct compression rate. It also ensures a correct compression depth-to-rate ratio. The need to identify too deep compressions was pointed out. Using the whole hand as opposed to the wrist gave better results. This may create doubts as to whether the compressions are performed on a too low part of the sternum. With a manikin that imitates a human being, creating and maintaining an open airway becomes a natural act.

\section{LIMITATIONS}

One limitation of this study is that it does not address the situation of resuscitation termination, it only addresses the skill regarding CPR. CPR is often performed in a situation that includes kin or bystanders. The firefighters must deal with life and death situations in the most challenging situations. The fact that ethical aspects of performing CPR are not at all comprised in this research is a clear limitation.

Conflict of interest: The Brayden Pro ${ }^{\circledR}$ manikin was provided free of charge by Innosonian Europe for the time needed for the study. No other financial arrangements were made.

\section{REFERENCES}

1. Monsieurs GK, Nolan JP, Bossaert LL, et al. European Resuscitation Council Guidelines for Resuscitation. Section 1. Executive summary. Resuscitation. 2015; 95: 1-80.

2. Perkins G, Handley A, Koster R, et al. European Resuscitation Council Guidelines for Resuscitation 2015. Section 2. Adult basic life support and automated external defibrillation. Resuscitation. 2015; 95: 81-99, doi: 10.1016/j.resuscitation.2015.07.015.
3. Hung SC, Mou CY, Hung HC, et al. Non-traumatic out-of-hospital cardiac arrest in rural Taiwan: A retrospective study. Aust J Rural Health. 2017; 25(6): 354-361, doi: 10.1111/ajr.12341, indexed in Pubmed: 28008683.

4. Hollenberg J, Riva G, Bohm K, et al. Dual dispatch early defibrillation in out-of-hospital cardiac arrest: the SALSA-pilot. Eur Heart J. 2009; 30(14): 1781-1789, doi: 10.1093/eurheartj/ehp177, indexed in Pubmed: 19474051.

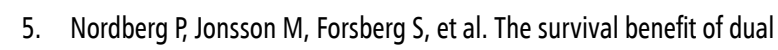
dispatch of EMS and fire-fighters in out-of-hospital cardiac arrest may differ depending on population density--a prospective cohort study. Resuscitation. 2015; 90: 143-149, doi: 10.1016/j.resuscitation.2015.02.036, indexed in Pubmed: 25790753.

6. Dyson K, Bray JE, Smith K, et al. Paramedic resuscitation competency: A survey of Australian and New Zealand emergency medical services. Emerg Med Australas. 2017; 29(2): 217-222, doi: 10.1111/1742-6723.12715, indexed in Pubmed: 28093867.

7. Greif R, Lockey AS, Conaghan $P$, et al. European Resuscitation Council Guidelines for Resuscitation 2015: Section 10. Education and implementation of resuscitation. Resuscitation. 2015; 95 : 288-301, doi: 10.1016/j.resuscitation.2015.07.032, indexed in Pubmed: 26477418.

8. Truhlář A, Deakin CD, Soar J, et al. European Resuscitation Council Guidelines for Resuscitation 2015: Section 4. Cardiac arrest in special circumstances. Resuscitation. 2015; 95: 148-201, doi: 10.1016/j. resuscitation.2015.07.017, indexed in Pubmed: 26477412.

9. Weston BW, Jasti J, Lerner EB, et al. Does an individualized feedback mechanism improve quality of out-of-hospital CPR? Resuscitation. 2017; 113: 96-100, doi: 10.1016/j.resuscitation.2017.02.004, indexed in Pubmed: 28215590.

10. Elo $S$, Kyngäs $H$. The qualitative content analysis process. J Adv Nurs. 2008; 62(1): 107-115, doi: 10.1111/j.1365-2648.2007.04569.x, indexed in Pubmed: 18352969.

11. Polit DG, Beck CT. Nursing research; Generating and Assessing Evidence for Nursing Practice. Lippincott, Philadelphia 2017.

12. World Medical Association Declaration of Helsinki. JAMA. 2013; 310(20): 2191-2194, doi: 10.1001/jama.2013.281053.

13. Idris AH, Guffey D, Pepe PE, et al. Resuscitation Outcomes Consortium Investigators. Chest compression rates and survival following out-of-hospital cardiac arrest. Crit Care Med. 2015; 43(4): 840-848, doi: 10.1097/CCM.0000000000000824, indexed in Pubmed: 25565457.

14. Alves GM, da Silva MC, Silva Bueno SJ, et al. Military skills of firefighters in cardiopulmonary resuscitation. Journal of nursing. 2017; 11(11): 4397-4403.

15. Lee K, Kim MJ, Park J, et al. The effect of distraction by dual work on a CPR practitioner's efficiency in chest compression: A randomized controlled simulation study. Medicine (Baltimore). 2017; 96(43): e8268, doi: 10.1097/MD.00000000000008268, indexed in Pubmed: 29068995.

16. Cheskes $S$, Schmicker RH, Rea $T$, et al. The association between AHA CPR quality guideline compliance and clinical outcomes 
from out-of-hospital cardiac arrest. Resuscitation. 2017; 116: 39-45, doi: 10.1016/j.resuscitation.2017.05.003, indexed in Pubmed: 28476474.

17. Stiell IG, Brown SP, Nichol G, et al. What is the optimal chest compression depth during out-of-hospital cardiac arrest resuscitation of adult patients? Circulation. 2014; 130(22): 1962-1970, doi: 10.1161/ CIRCULATIONAHA.114.008671, indexed in Pubmed: 25252721.

18. Kleinman ME, Brennan EE, Goldberger ZD, et al. Part 5: Adult Basic Life Support and Cardiopulmonary Resuscitation Quality: 2015 American Heart Association Guidelines Update for Cardiopulmonary Resuscitation and Emergency Cardiovascular Care. Circulation. 2015; 132(18 Suppl 2): S414-S435, doi: 10.1161/CIR.0000000000000259, indexed in Pubmed: 26472993.

19. Vadeboncoeur T, Stolz U, Panchal A, et al. Chest compression depth and survival in out-of-hospital cardiac arrest. Resuscitation. 2014; 85(2): 182-188, doi: 10.1016/j.resuscitation.2013.10.002.

20. Cha KC, Kim HoJ, Shin HJ, et al. Hemodynamic effect of external chest compressions at the lower end of the sternum in cardiac arrest patients. J Emerg Med. 2013; 44(3): 691-697, doi: 10.1016/j. jemermed.2012.09.026, indexed in Pubmed: 23218197.

21. Qvigstad E, Kramer-Johansen Jo, Tømte $\varnothing$, et al. Clinical pilot study of different hand positions during manual chest compressions monitored with capnography. Resuscitation. 2013; 84(9):
1203-1207, doi: 10.1016/j.resuscitation.2013.03.010, indexed in Pubmed: 23499897.

22. Truszewski Z, Szarpak L, Kurowski A, et al. Randomized trial of the chest compressions effectiveness comparing 3 feedback CPR devices and standard basic life support by nurses. Am J Emerg Med. 2016; 34(3): 381-385, doi: 10.1016/j.ajem.2015.11.003, indexed in Pubmed: 26612703.

23. DeBoer $S$, Braude $D$, Seaver $M$, et al. Alternative Airways: The Who, What, Where, When and How. EMS World. 2015; 44(10): 38-40, 42, 46, indexed in Pubmed: 26554215.

24. March JA, Tassey TE, Resurreccion NB, et al. Comparison of the I-gel supraglottic and king laryngotracheal airways in a simulated tactical environment. Prehosp Emerg Care. 2018; 22(3): 385-389, doi: 10.1080/10903127.2017.1399183, indexed in Pubmed: 29364743.

25. Jarman $A F$, Hopkins $C L$, Hansen $J N$, et al. Advanced airway type and its association with chest compression interruptions during out-of-hospital cardiac arrest resuscitation attempts. Prehosp Emerg Care. 2017; 21(5): 628-635, doi: 10.1080/10903127.2017.130861 1, indexed in Pubmed: 28459305.

26. Kim KiH, Shin SDo, Song KJ, et al. Scene time interval and good neurological recovery in out-of-hospital cardiac arrest. Am J Emerg Med. 2017; 35(11): 1682-1690, doi: 10.1016/j.ajem.2017.05.049, indexed in Pubmed: 28592372. 